\title{
Delayed Sealing of WATCHMAN Device Shunt
}

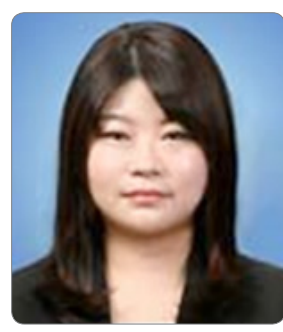

Young-Ah Park, MD; Jung-Sun Kim, MD, PhD; Hui-Nam Pak, MD, PhD

Yonsei University Health System, Seoul, Republic of Korea

Received: February 23, 2017

Revision Received: March 17, 2017

Accepted: March 23, 2017

Correspondence: Hui-Nam Pak, MD, PhD

Yonsei University Health System, 50 Yonsei-ro,

Seodaemun-gu, Seoul 03722, Republic of Korea

Tel: $+82-2-2228-8459$

Fax: +82-2-393-2041

E-mail: hnpak@yuhs.ac

Copyright (c) 2017 The Official Journal of Korean Heart Rhythm Society Editorial Board \& MMK Co., Ltd.

\begin{abstract}
Although left atrial appendage closure is an alternative to warfarin use in atrial fibrillation patients with a high bleeding risk, long-term outcome data in real-world practice are still limited. We describe a delayed shunt on the WATCHMAN fabric membrane and associated stroke at 7 months after the procedure. This shunt on the device surface disappeared at 15 months on the follow-up transesophageal echocardiogram.
\end{abstract}

Key Words: - Left Atrial Appendage • Stroke - Anticoagulants

\section{Introduction}

Increased risk of ischemic stroke in patients with atrial fibrillation (AF) emphasizes the importance of anticoagulation therapy for stroke prevention. ${ }^{1}$ Left atrial appendage (LAA) closure is considered an alternative to warfarin in patients with higher bleeding risk. LAA closure with the WATCHMAN device reportedly has a high successful implantation rate with low periprocedural risk of complications, ${ }^{2}$ and long-term safety comparable to that of warfarin. ${ }^{3,4}$ However, long-term clinical outcome data in real-world practice are still limited. ${ }^{5}$ The time to complete endothelial coverage of the device surface has not been clearly documented in humans. ${ }^{6}$ Herein, we describe a long-term complication after LAA closure, with delayed perforation of the WATCHMAN fabric membrane and associated stroke at 7 months after the procedure. The device shunt showed delayed disappearance after 15 months.

\section{Case}

A 69-year-old man with a history of hypertension, congestive heart failure, and persistent $\mathrm{AF}\left(\mathrm{CHA}_{2} \mathrm{DS}_{2}\right.$-VASc score 3$)$ was admitted. Because of a previous history of gastric bleeding during oral anticoagulation with warfarin, LAA closure was considered. A 27-mm WATCHMAN (Boston Scientific, Plymouth, MA, USA) device was successfully implanted on the initial attempt without acute procedure-related complications. A transesophageal echocardiogram (TEE) immediately after implantation and 8 weeks later showed adequate positioning without evident peridevice leakage. After 8 weeks of postprocedure anticoagulation, warfarin was changed to dual antiplatelet therapy with aspirin and clopidogrel.

Seven months after LAA occlusion, the patient was admitted to the emergency room with sudden dysarthria, and was diagnosed with multiple embolic cerebral infarctions on brain magnetic resonance imaging (Figure 1A). The patient was in sinus 


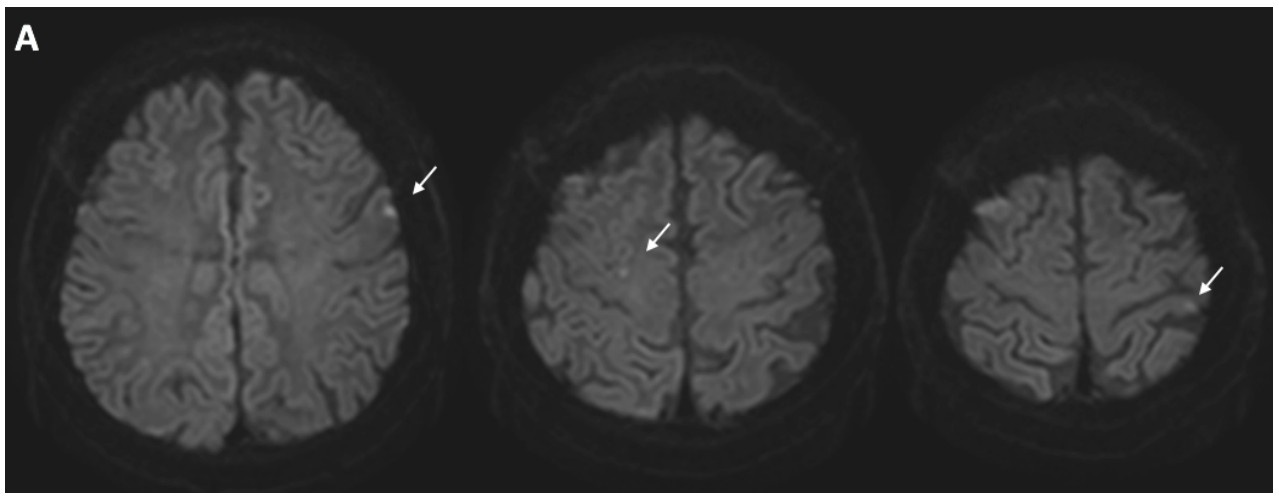

Figure 1. Brain MRI after admission for dysarthria revealed multiple embolic infarctions in the left postcentral gyrus with diffuse old ischemic lesions (arrows).

A

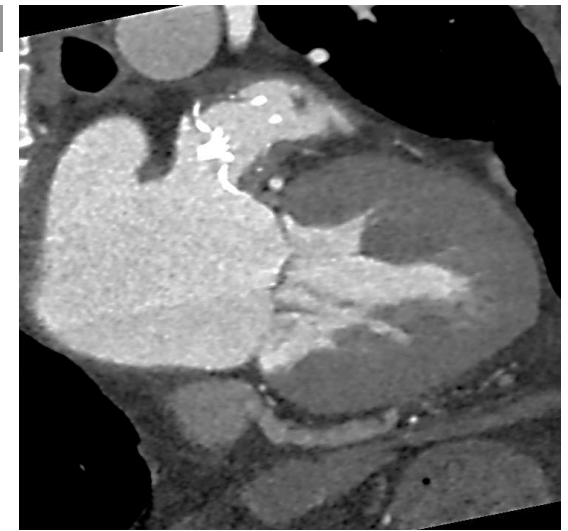

B

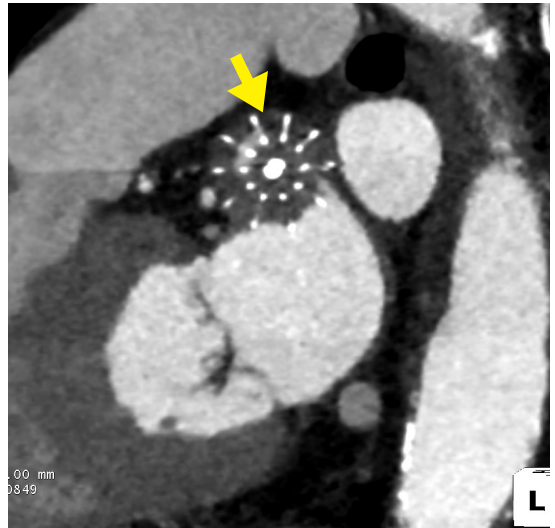

Figure 2. A and B. CT after stroke (reconstructed to show the WATCHMAN axis) shows central contrast filling of the device (arrow).

rhythm on admission. Central contrast filling in the LAA device was observed on cardiac computed tomography (CT) (Figure 1B and $1 \mathrm{C}$ ), and to-and-fro flow communication at the center of the device and multiple thrombi were visible on the TEE (Figure $2 \mathrm{~A}$ and $2 \mathrm{~B}$, Movie 1). At this time, we reexamined the 8-week postprocedure TEE, and a faint central jet with inward flow to the LAA was suspected (Movie 2).

The patient recovered on apixaban without neurologic sequelae and was followed without further events. The central communicating flow disappeared and organized thrombus filling the inner space of the device was observed at 15 months after the procedure (Movie 3).

\section{Discussion}

The WATCHMAN device has established use for LAA closure, and is an alternative to chronic oral anticoagulation in patients with nonvalvular AF at high risk for thromboembolism and bleeding. ${ }^{7.8}$ The noninferiority of the WATCHMAN device to warfarin in ischemic stroke and major bleeding was shown in randomized controlled trials. ${ }^{3,7,8}$ A study of 1,004 patients with successful WATCHMAN implantation reported acute procedure-related complications in $2.8 \%$ within 7 days, and $7.9 \%$ had serious adverse events including major bleeding, pericardial effusion, vascular damage, procedural air embolism, device embolization, and peri-device leakage within 30 days after the 

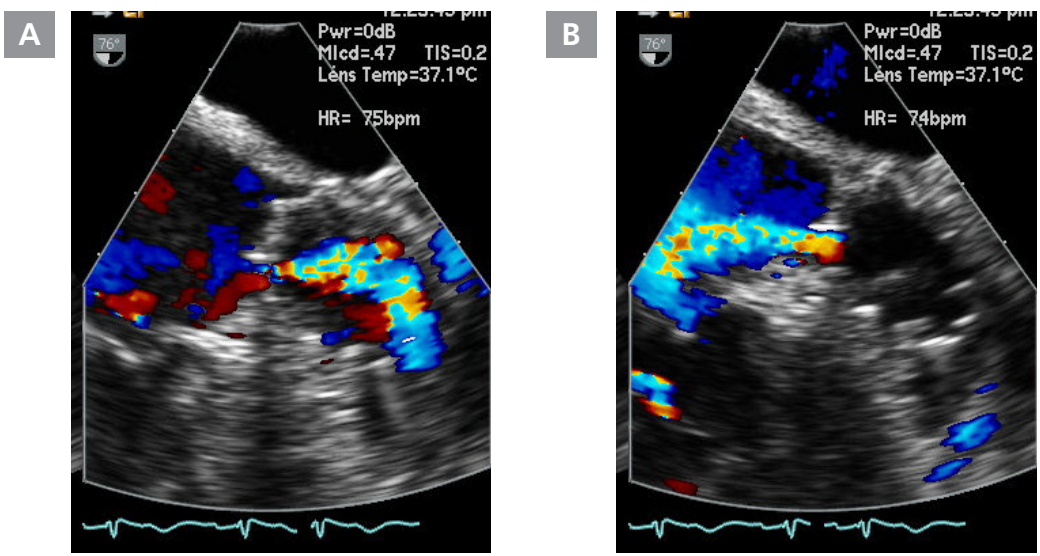

Figure 3. A and $\mathrm{B}$. TEE (at $75^{\circ}$ ) after admission for stroke. To-and-fro flow communication was observed at the center of the device.

procedure. ${ }^{2}$ However, delayed complications related to suspected device perforation have not yet been reported.

The device comprises a nitinol frame and a fabric membrane. Although the device was implanted successfully in a single attempt, the thin fabric membrane could have been damaged by device manipulation or deployment. Alternatively, spontaneous restoration of sinus rhythm may have improved LAA contractility in this case; this might have unmasked a preexisting, unnoticed small defect on the device. Although the patient was in AF at 15 months of follow-up, the central communicating flow had disappeared. Therefore, delayed endothelialization should be considered in patients with contrast filling of the LAA on followup cardiac CT. ${ }^{6}$ If device-related thrombus formation or peridevice leakage is observed, extended anticoagulation may be considered. 5 .9 To determine the duration of anticoagulation, serial imaging should be performed until complete endothelialization of the device is likely.

\section{Conclusion}

This is the first reported case of delayed sealing of an LAA closure device shunt, highlighting the need for close observation and serial imaging.

\section{Conflict of interest}

none declared

\section{Supplementary Material}

Movie 1. Transesophageal echocardiogram at the time of admission for stroke, 7-month after procedure (90-degree view) (doi: http://dx.doi.org/10.18501/arrhythmia.2017.010.m001)

Movie 2. Transesophageal echocardiogram at 8 weeks after LAA occlusion (45-degree view) (doi: http://dx.doi. org/10.18501/arrhythmia.2017.010.m002)

Movie 3. Transesophageal echocardiogram at 15 months after LAA occlusion (90-degree view) (doi: http://dx.doi. org/10.18501/arrhythmia.2017.010.m003)

\section{References}

1) Wolf PA, Abbott RD, Kannel WB. Atrial fibrillation: a major contributor to stroke in the elderly. The Framingham Study. Arch Intern Med. 1987;147:1561-1564.

2) Boersma LV, Schmidt B, Betts TR, Sievert H, Tamburino C, Teiger E, Pokushalov E, Kische S, Schmitz T, Stein KM, Bergmann MW. Implant success and safety of left atrial appendage closure with the WATCHMAN device: peri-procedural outcomes from the EWOLUTION registry. Eur Heart J. 2016;37:2465-2474.

3) Reddy VY, Doshi SK, Sievert H, Buchbinder M, Neuzil P, Huber K, Halperin JL, Holmes D. Percutaneous left atrial appendage closure for stroke prophylaxis in patients with atrial fibrillation: 2.3Year Follow-up of the PROTECT AF (Watchman Left Atrial Appendage System for Embolic Protection in Patients with Atrial 
Fibrillation) trial. Circulation. 2013;127:720-729.

4) De Backer O, Arnous S, Ihlemann N, Vejlstrup N, Jorgensen E, Pehrson S, Krieger TD, Meier P, Sondergaard L, Franzen OW. Percutaneous left atrial appendage occlusion for stroke prevention in atrial fibrillation: an update. Open Heart. 2014;1:e000020.

5) Kim JS, Lee H, Suh Y, Pak HN, Hong GR, Shim CY, Yu CW, Lee HJ, Kang WC, Shin ES, Choi RK, Kar S, Park JW, Lim DS, Jang Y. Left atrial appendage occlusion in non-valvular atrial fibrillation in a Korean Multi-Center Registry. Circ J. 2016;80:1123-1130.

6) Youn JC, Pak HN, Kwon HJ, Kang SM. Watch out for the WATCHMAN. Eur Heart J. 2015;36:1648.

7) Reddy VY, Holmes D, Doshi SK, Neuzil P, Kar S. Safety of percutaneous left atrial appendage closure: results from the Watchman Left Atrial Appendage System for Embolic Protection in Patients with AF (PROTECT AF) clinical trial and the Continued Access Registry. Circulation. 2011;123:417-424.

8) Holmes DR, Jr., Kar S, Price MJ, Whisenant B, Sievert H, Doshi SK, Huber K, Reddy VY. Prospective randomized evaluation of the Watchman Left Atrial Appendage Closure device in patients with atrial fibrillation versus long-term warfarin therapy: the PREVAIL trial. J Am Coll Cardiol. 2014;64:1-12.

9) Meier B, Blaauw Y, Khattab AA, Lewalter T, Sievert H, Tondo C, Glikson M. EHRA/EAPCI expert consensus statement on catheter-based left atrial appendage occlusion. Europace. 2014;16:1397-1416. 